\title{
STUDY ON ACRYLAMIDE ACCUMULATION IN THE MODEL SYSTEM BASED ON ANIMAL RAW MATERIALS DEPENDING ON THERMAL TREATMENT REGIMES
}

\author{
Andrei S. Dydykin, ${ }^{1 "}$ Olga K. Derevitskaya, ${ }^{1}$ Andrew N. Ivankin, ${ }^{1,2}$ \\ Andrey V. Kulikovskii, ${ }^{1}$ Ekaterina I. Dragunskaya ${ }^{1}$ \\ ${ }^{1}$ V.M. Gorbatov Federal Research Center for Food Systems of Russian Academy of Sciences, Moscow, Russia \\ ${ }^{2}$ Bauman Moscow State Technical University, Moscow, Russia
}

KEY WORDS:

acrylamide, model meat composition, amino acid composition, aspartic acid, reducing sugars, thermal treatment

\begin{abstract}
:
The aim of the investigation was to study an effect of thermal treatment parameters on the content of reducing sugars, amino acids and acrylamide in the meat model system depending on the thermal treatment regime. The authors studied an influence of the reaction of melanoidine formation on the concentration of amino acids and reducing sugars at different thermal treatment regimes and established a decrease in the total amino acid content by $7 \%$ upon the standard sterilization regime and by $11 \%$ when increasing the temperature or duration of thermal treatment. It was found that at the same temperature with an increase in duration of thermal treatment up to $50 \mathrm{~min}$., the acrylamide level increased by 1.6 times. Exposure of the model samples to a temperature of $120^{\circ} \mathrm{C}$ for $50 \mathrm{~min}$. had the highest effect on the level of acrylamide accumulation compared to the traditional sterilization regime of canned foods for child nutrition and the regime with an increased temperature of up to $130{ }^{\circ} \mathrm{C}$ The obtained data will allow developing new meat products with the reduced content of unsafe components for nutrition in early childhood.
\end{abstract}

\section{Introduction}

During thermal processing of foods, many various chemical reactions take place, which lead to changes in their composition and formation of new compounds. The Maillard reaction or the reaction of melanoidine formation is prevalent among occurring reactions; it occurs in a wide range of temperatures, humidity, presence or absence of oxygen and so on [1].

Acrylamide $(\mathrm{C} 3 \mathrm{H} 5 \mathrm{NO})$ is a carcinogenic substance, which is formed in the reaction between asparagine and sugars (fructose, glucose and so on) at high temperatures. Since 1950, it has been used in the organic synthesis and in production of plastics. The median lethal dose of acrylamide for laboratory animals was $150-180 \mathrm{mg} / \mathrm{kg}$; therefore, this substance is assigned to the 2nd class of hazards [2,3]. The elimination half-life of acrylamide in rats is about $2 \mathrm{~h}$.

Toxicity of acrylamide is conditioned by the small molecular weight, small molecular size, high water solubility and comparatively easy penetration into the human body though the gastrointestinal tract and skin. Acrylamide can exert the most negative effect on the child body due to the low body weight [4]. In childhood, the sensitivity to the impact of different contaminants in foods is higher. It is associated with an increased permeability of protective barriers for foreign subjects, including toxic substances, and immaturity of the immune and enzyme systems [5].

Acrylamide, which is formed in the process of the technological treatment of foods, is recognized by World Health Organization as a genotoxic carcinogen [6,7]. When ingested, it is easily absorbed through the gastrointestinal tract and is distributed over the whole body negatively affecting human health.

It is known that acrylamide is formed in several food products in the process of thermal treatment at a temperature of $120{ }^{\circ} \mathrm{C}$ and higher as a result of the protein-carbohydrate interaction. With that, in formation of the acrylamide molecule, the main nitrogen source is amino acid asparagine, which reacts with reducing sugars in the process of heating [6]. As a result of the Maillard reaction, decomposition of both the initial amino acid and reducing sugar that reacts with it takes place.
Beginning from 2000, different countries have been testing various methods for quantitative determination of the acrylamide content in food products. Among them, the high performance liquid chromatography with mass spectrometric detection and gas chromatography are the most widely used methods. Based on the investigations carried out in different countries, the Joint FAO/WHO Expert Committee on Food Additives (JECFA) concluded that safe dietary intake of acrylamide can be $1 \mathrm{\mu g} /$ $1 \mathrm{~kg}$ body weight / day [7,8,9,10].

Therefore, knowing the mechanism of acrylamide formation, it is possible to suggest quite a high probability of its formation in plant-and-meat canned foods as a result of interaction of fructose and glucose containing components and aspartic acid, which is present in meat.

In this connection, it is urgent to carry out studies on detection and quantification of acrylamide in meat containing canned foods for nutrition in early childhood, which results could be used to establish a safe limit of its content in canned foods for child nutrition and make corresponding proposals into Technical Regulations of the Customs Union regarding its control.

Also, as a result of investigations it is necessary to determine possible ways for reducing a risk of acrylamide formation in canned foods. One of such ways is correction of the sterilization equation as, at present, the used thermal treatment regimes, in particular, for meat-based canned foods for child nutrition often have too high temperature and duration of sterilization, which, first of all, negatively affect nutritional value of a product and, secondly, increases risks of development of negative compounds $[11,12]$.

The aim of the work was to study the effect of the parameters of thermal treatment on the content of reducing sugars, amino acids and acrylamide in a meat model system depending on a thermal treatment regime.

\section{Materials and methods}

The object of the research was the model recipe composition made in the homogenized form (particle size not more than $0.3 \mathrm{~mm}$ ) from beef (41\%), soy isolated protein (4\%), wheat 
flour (5\%), water (50\%), heated to a temperature of $85^{\circ} \mathrm{C}$ and sterilized in $100 \mathrm{ml}$ glass jars under the following regimes:

$$
\begin{aligned}
& \left.\frac{20-30-20}{120} \text { (control); } \frac{20-50-20}{120} \text { (sample } 1\right) \text {; } \\
& \left.\frac{20-30-20}{130} \text { (sample } 2\right) \text {; where, the time of heating - actual }
\end{aligned}
$$

sterilization - cooling is indicated in the numerator; while the sterilization temperature is indicated in the denominator.

The production sterilization regime used in the technology of canned meat for child nutrition was used as a control. The sterilization regimes of the experimental samples differed from the control by an increased values of sterilization duration for sample 1 and sterilization temperature for sample 2 .

Amino acid composition was determined by GOST 34132- 2017 "Meat and meat products. Determination of amino acids composition of animal protein" [13,14]. The acrylamide content in the samples was determined according to the developed method.

Acrylamide was extracted with acetonitrile from a previously homogenized sample. A weighted specimen of a homogenized sample ( $3 \mathrm{~g}$ ) was placed into the $50 \mathrm{~cm}^{3}$ centrifugal tube and $8 \mathrm{ml}$ of acetonitrile was added. Six gram of magnesium sulfate and $1.5 \mathrm{~g}$ of sodium acetate were put into the centrifugal tube and agitated. The centrifugation was performed at 4,000 rpm for $5 \mathrm{~min}$. Addition of salts (magnesium sulfate and sodium acetate) leads to an increase in the recovery of the polar compounds, and also is used to control the percent of the water content in the organic layer (and vice versa); thereby, providing an opportunity to regulate a degree of polarity of both phases. To purify from organic impurities, an anion-exchange sorbent based on ethylenediamine-N-propyl, which extracts strongly acidic and polyacidic compounds and metal ions from aqueous solutions (particle size, $50 \mu \mathrm{m}$; pore diameter, $60 \AA$ ) was used. For additional purification of the aliquot, the C18(EC) sorbent was used; it was a silica non-polar silanized sorbent (octadecyl). Due to the hydrophobic interactions, C18(EC) is capable of extracting neutral basic and acidic compounds (particle size, 50 $\mu \mathrm{m}$; pore diameter, $60 \AA$ ). For this, an aliquot from the top part of the extract was taken and transferred to a $15 \mathrm{~cm}^{3}$ centrifugal tube, which contained $1.2 \mathrm{~g}$ of magnesium sulfate and $0.4 \mathrm{~g}$ of ethylenediamine-N-propyl. The centrifugation was carried out at 4,000 rpm for $5 \mathrm{~min}$.. The purified extract was passed through a $0.45 \mu \mathrm{m}$ membrane filter, transferred to a vial and analyzed by HPLC- MS/MS. The method requires the strict sequence of reagent addition as it is necessary to add salts after the organic solvent addition. Addition of salts directly into a sample can cause an exothermic reaction, which can negatively affect acrylamide recovery. Figure 1 presents a chromatogram of the sample with acrylamide after extraction and purification.

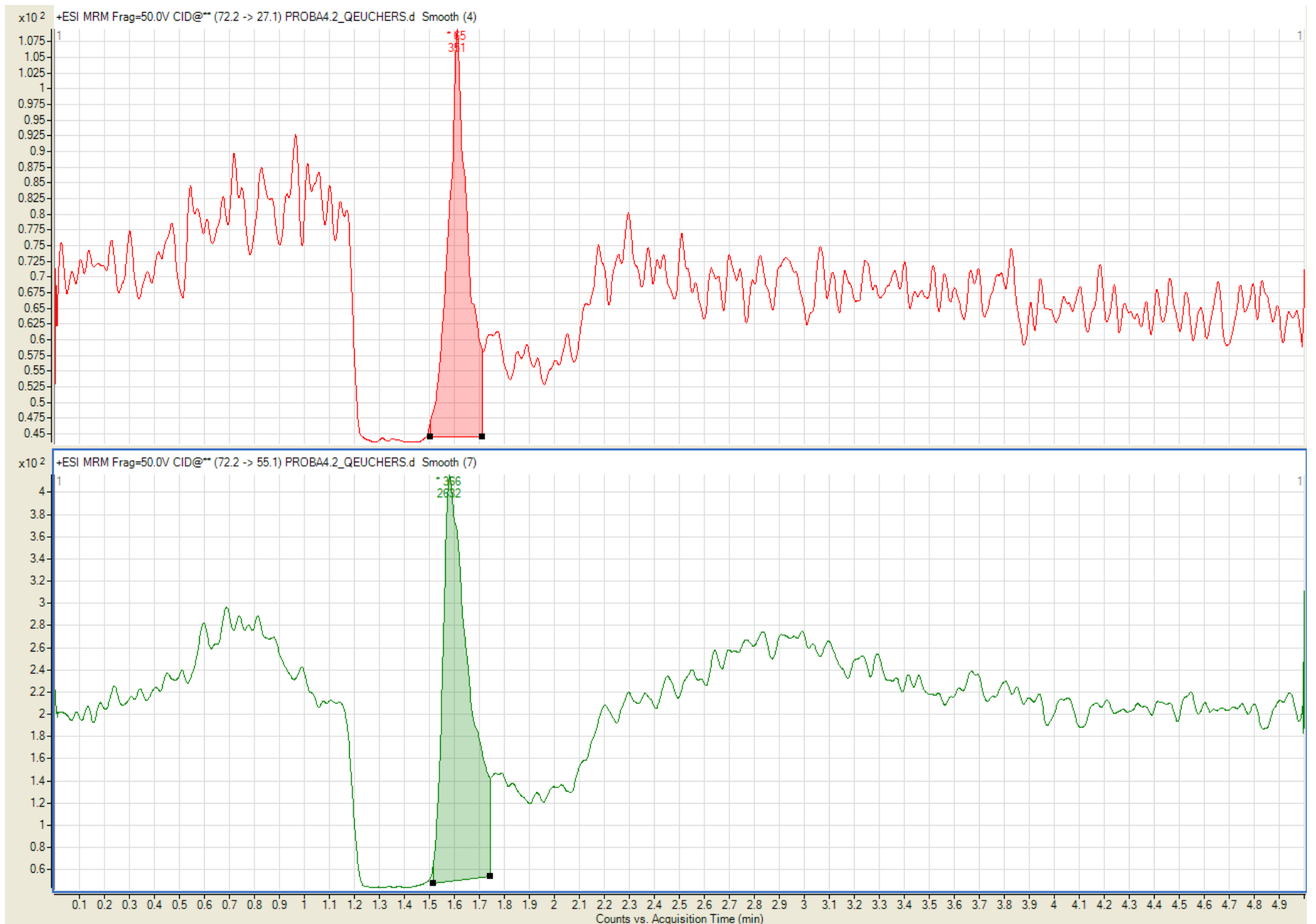

Figure 1. The chromatogram of the sample with acrylamide after extraction and purification.

Analysis of acrylamide was carried out on the system of high performance liquid chromatography Agilent1200 (USA) with a triple quadrupole mass spectrometer Agilent 6410B equipped with an electrospray ionization (ESI) source. For acrylamide detection, a chromatographic column Zorbax HILIC
Plus (Agilent Technologies, USA) was used. This column is recommended for separation of small polar substances by the method of hydrophilic interaction chromatography. Separation was carried out in the mode of gradient elution (two component mobile phase): the volume of the injected sample $-0.02 \mathrm{~cm}^{3}$; 

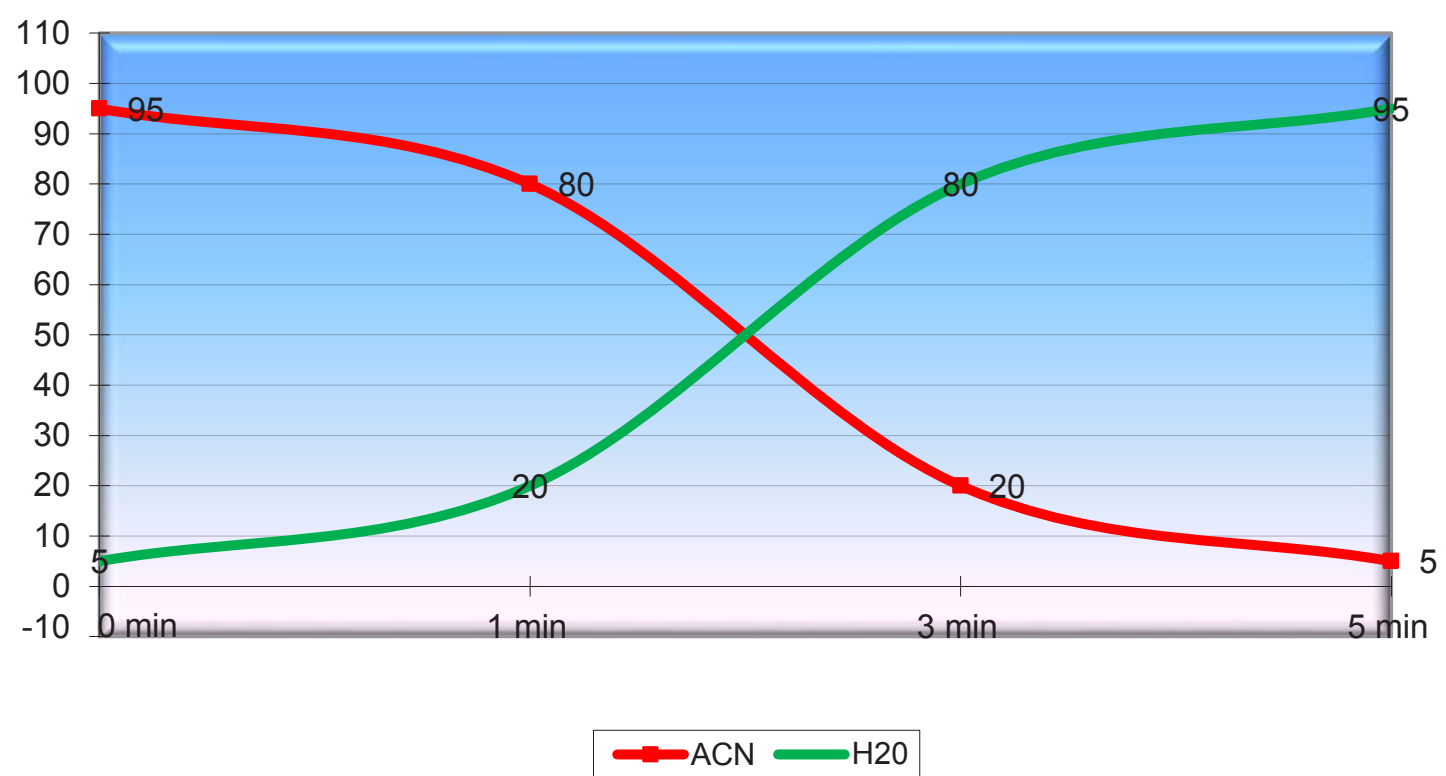

Figure 2. Parameters of chromatographic separation with separation on a column for hydrophilic interaction chromatography Zorbax HILIC Plus.

the mobile phase flow rate $-1.0 \mathrm{~cm}^{3} / \mathrm{min}$; the temperature of the column thermostat $-40{ }^{\circ} \mathrm{C}$. Parameters and conditions of HPLC separation are presented in Figure 2.

As a result of the performed investigations, the detection conditions were optimized:

Source temperature $-100^{\circ} \mathrm{C}$;

Desolvation gas temperature $-320^{\circ} \mathrm{C}$;

Flow rate of desolvation gas $-8 \mathrm{dm}^{3} / \mathrm{min}$;

Pressure of atomizer needle- $30 \mathrm{psi}(206.85 \mathrm{kPa})$.

Table 1.

Parameters of the impact on ions in the MRM mode and conditions of electrospray ionization (ESI) with registration of positive $(+)$ and $(-)$ negative ions

\begin{tabular}{|l|c|c|c|c|}
\hline Analyte & $\begin{array}{c}\text { Molecular } \\
\text { ion, m/z }\end{array}$ & $\begin{array}{c}\text { Daughter } \\
\text { ions, m/z }\end{array}$ & $\begin{array}{c}\text { Fragmentor } \\
\text { voltage } \\
\text { (Frag), B }\end{array}$ & $\begin{array}{c}\text { Dissociation } \\
\text { energy } \\
\text { (CE), B }\end{array}$ \\
\hline Acrylamide & 72.2 & 27.1 & 50 & 5 \\
\hline Acrylamide & 72.2 & 55.1 & 50 & 15 \\
\hline
\end{tabular}

The conditions of analytical signal registration in the mode of multiple reaction monitoring $(M R M)$ are presented in Table 1.

The reliability of the results was confirmed by three replications of experiments.

The investigation was carried out in the laboratories of the V.M. Gorbatov Federal Research Center for Food Systems of the Russian Academy of Sciences.

\section{Results and discussions}

To simulate the technological process of production of canned meat products for nutrition in early childhood, prepared meat raw materials and components were mixed, minced on the equipment for dispersion and homogenization and then heated to a temperature of $85^{\circ} \mathrm{C}$. A sample was taken from the obtained model formulation for quantification of free carbohydrates and amino acid composition. Then the model formulation was filled into glass jars, sealed and sterilized under the regimes indicated in the section "Materials and methods". To intensify the reaction of melanoidin formation, the composition was sterilized with increased duration and the temperature of sterilization.

Heating of sugars at temperatures above $100{ }^{\circ} \mathrm{C}$ in a weak acidic environment leads to formation of a complex product mixture, which properties and composition change depending on the degree of an environment impact, sugar type and concentration, conditions of heating. The results of changes in

Content of sugars in the model formulation

Table 2.

\begin{tabular}{|l|c|c|c|c|}
\hline \multicolumn{1}{|c|}{ Content of sugars in the model formulation } \\
\hline Sugars & $\begin{array}{c}\text { Content, \% (g/100 g) of sample } \\
\text { Model } \\
\text { formulation after } \\
\text { heating to 85 } \mathbf{~}^{\circ} \mathbf{C}\end{array}$ & control & $\begin{array}{c}\text { sample } \\
\text { No. 1 }\end{array}$ & $\begin{array}{c}\text { sample } \\
\text { No.2 }\end{array}$ \\
\hline Arabinose & 0.13 & 0.09 & 0.015 & 0.014 \\
\hline Galactose & 0.06 & 0.03 & 0.013 & 0.009 \\
\hline Glucose & 0.14 & 0.34 & 0.24 & 0.13 \\
\hline Xylose & 0.006 & 0.008 & 0.005 & 0.002 \\
\hline Fructose + \\
saccharose & 5.9 & 3.8 & 0.001 & 0.12 \\
\hline Ribose & 0 & 0 & 0.14 & 0.031 \\
\hline Total & 6.236 & 4.268 & 0.414 & 0.306 \\
\hline
\end{tabular}

the content of reducing sugars in the model system are presented in Table 2.

In analysis of the obtained data (Table 2), it was established that the total amount of sugars decreased as a result of the reaction of acrylamide formation with participation of aspartic acid after high temperature thermal treatment (sterilization) in sample No. 1 and increased treatment duration in sample No.2 by $93.2 \%$ and $94.7 \%$, respectively, compared to the sample before sterilization heated to $85^{\circ} \mathrm{C}$. With that, a decrease in the control sample was $31.6 \%$, which was conditioned, apparently, by the sterilization regime with a lower thermal load.

In the course of the Maillard reaction, amino acids are bound and a decrease in the biological value of proteins is observed. The model formulation was studied by the content of amino acids. The results of the analysis of amino acid composition are presented in Table 3.

By the results of the analysis of the amino acid composition in the experimental samples, it was found that the sum of amino acids in the model composition decreased by $7 \%$ for the control and by $11 \%$ for samples 1 and 2 compared to the sample before sterilization. With that, a reduction in the content of aspartic acid participating in acrylamide formation compared to the 
Amino acid composition in the model formulations

Table 3.

Content (g/100 g product)

\begin{tabular}{|c|c|c|c|c|c|}
\hline \multirow[b]{2}{*}{ No. } & \multirow[b]{2}{*}{ Amino acids } & \\
\hline & & $\begin{array}{l}\text { Model formulation after } \\
\text { heating up to } 85^{\circ} \mathrm{C}\end{array}$ & control & sample No. 1 & sample No.2 \\
\hline 1 & Aspartic acid & $1.55 \pm 0.05$ & $1.44 \pm 0.04$ & $1.36 \pm 0.04$ & $1.35 \pm 0.04$ \\
\hline 2 & Glutamic acid & $1.40 \pm 0.04$ & $1.34 \pm 0.04$ & $1.30 \pm 0.04$ & $1.29 \pm 0.04$ \\
\hline 3 & Serine & $0.70 \pm 0.02$ & $0.67 \pm 0.02$ & $0.63 \pm 0.02$ & $0.65 \pm 0.02$ \\
\hline 4 & Histidine & $0.49 \pm 0.01$ & $0.43 \pm 0.01$ & $0.45 \pm 0.01$ & $0.48 \pm 0.01$ \\
\hline 5 & Glycine & $0.80 \pm 0.02$ & $0.77 \pm 0.02$ & $0.72 \pm 0.02$ & $0.70 \pm 0.02$ \\
\hline 6 & Threonine & $0.56 \pm 0.02$ & $0.52 \pm 0.02$ & $0.49 \pm 0.01$ & $0.51 \pm 0.02$ \\
\hline 7 & Arginine & $0.66 \pm 0.02$ & $0.62 \pm 0.02$ & $0.61 \pm 0.02$ & $0.59 \pm 0.02$ \\
\hline 8 & Alanine & $0.78 \pm 0.02$ & $0.73 \pm 0.02$ & $0.70 \pm 0.02$ & $0.69 \pm 0.02$ \\
\hline 9 & Tyrosine & $0.34 \pm 0.01$ & $0.31 \pm 0.01$ & $0.30 \pm 0.01$ & $0.30 \pm 0.01$ \\
\hline 10 & Cystine & $0.78 \pm 0.02$ & $0.77 \pm 0.02$ & $0.71 \pm 0.02$ & $0.69 \pm 0.02$ \\
\hline 11 & Valine & $1.20 \pm 0.04$ & $1.15 \pm 0.03$ & $1.11 \pm 0.03$ & $1.10 \pm 0.03$ \\
\hline 12 & Methionine & $0.60 \pm 0.02$ & $0.54 \pm 0.02$ & $0.55 \pm 0.02$ & $0.52 \pm 0.02$ \\
\hline 13 & Phenylalanine & $0.47 \pm 0.01$ & $0.43 \pm 0.01$ & $0.46 \pm 0.01$ & $0.47 \pm 0.01$ \\
\hline 14 & Isoleucine & $0.58 \pm 0.02$ & $0.53 \pm 0.02$ & $0.51 \pm 0.02$ & $0.55 \pm 0.02$ \\
\hline 15 & Leucine & $0.69 \pm 0.02$ & $0.60 \pm 0.02$ & $0.56 \pm 0.02$ & $0.52 \pm 0.02$ \\
\hline 16 & Lysine & $0.62 \pm 0.02$ & $0.58 \pm 0.02$ & $0.55 \pm 0.02$ & $0.59 \pm 0.02$ \\
\hline 17 & Proline & $0.85 \pm 0.03$ & $0.77 \pm 0.02$ & $0.69 \pm 0.02$ & $0.70 \pm 0.02$ \\
\hline \multicolumn{2}{|l|}{ Total } & $13.07 \pm 0.39$ & $12.20 \pm 0.37$ & $11.69 \pm 0.35$ & $11.69 \pm 0.35$ \\
\hline
\end{tabular}

control was found in the higher degree in the experimental samples, which were characterized by the increased duration and temperature of sterilization.
An effect of duration and temperature of the reaction on a level of acrylamide formation in the meat model system was studied. The obtained results are presented in Figure 3.

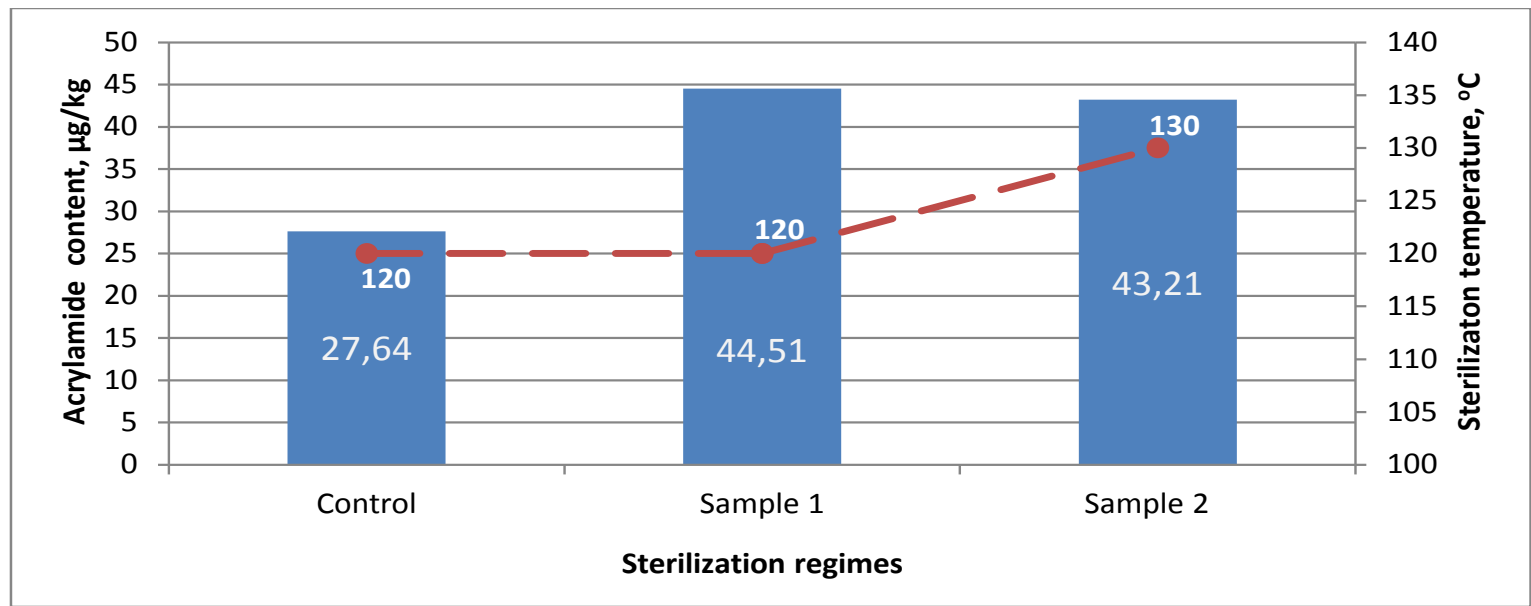

Figure 3. Acrylamide content in the model composition

In the sample produced using the traditional regime of sterilization (control), the acrylamide content was $27.64 \mu \mathrm{g} /$ $\mathrm{kg}$. It was established that at the same temperature, a level of acrylamide increased 1.6 times with an increase in the thermal treatment duration up to $50 \mathrm{~min}$. When a temperature was increased up to $130{ }^{\circ} \mathrm{C}$ upon the same duration, an amount of acrylamide increased by 1.5 times. That is, duration of the thermal treatment had somewhat higher effect on the level of acrylamide in the model composition. The obtained data correspond to the results $[15,16,17]$, which indicate that a decrease in the temperature and duration of food thermal processing leads to a decrease in the level of acrylamide formation.

\section{Conclusion}

As a result of the study on the effect of the melanoidin formation reaction on the concentration of amino acids and reducing sugars at different thermal treatment regimes, it was established that the total content of amino acids decreased by $7 \%$ at the standard regime of sterilization and by $11 \%$ when the temperature or duration of thermal treatment were increased. It was established that at the same temperature, the acrylamide level increased 1.6 times with an increase in the duration of thermal treatment up to $50 \mathrm{~min}$. Long-term exposure of the model samples to the temperature of $120^{\circ} \mathrm{C}$ for $50 \mathrm{~min}$. has the highest effect on the level of acrylamide accumulation compared to the traditional sterilization regime for canned foods for child nutrition and the regime with an increased temperature of up to $130{ }^{\circ} \mathrm{C}$.

It is necessary to take into consideration the obtained data when developing new meat product technologies for nutrition in early childhood with the maximum preservation of their chemical composition, as well as nutritional and biological value. 


\section{REFERENCES}

1. Pochitskaya, I.M., Roslyakov, Yu.F., Litvyak, V.V.,Komarova, N.V., Yudento. A.N. (2018). Investigation of the influence of the melanoidin formation reaction on the content of amino acids in model food systems. Voprosy Pitaniia, 87(5), 95-101. (In Russian)

2. Lazarev, N.V., Levina, N.V. (1976). Hazardous substances in industry. Reference book for chemists, engineers and physicians. V. 1. M: Chimiya, -595 p. (In Russian)

3. Dydykin, A. S., Derevitskaya, O. K. (2018). The problem of safety of child nutrition products subjected to high temperature treatment. Food Industry, 3, 58-59. (In Russian)

4. Kon, I. Ya., Konovalova, L.S., Georgieva, O.V. (2013). Issues of the support of the quality and safety of baby food. Hygiene and sanitation, 92(1), 36-39. (In Russian)

5. Dydykin, A.S., Derevitskaya, O.K., Dragunskaya, E.I. (2017). Acrylamide as the safety indicator in meat containing canned foods for child nutrition. International scientific and practical conference dedicated to the memory of Vasily Matveyevich Gorbatov, 1, 107-108. (in Russian).

6. Health Implications of acrylamide in food Report of Joint FAO. WHO Consultasion. Geneva: WHO Headqarters. - 2002. - 35 p.

7. Acrylamide. The toxicological evaluation of compounds on the agenda. Evaluation of certain food contaminants: sixty- fourth report of the Joint FAO. Geneva: WHO Expert Committee on Food Additives. - 2005.- pp. 8-26.

8. International Food Safety Authorities Network (INFOSAN). INFOSAN information note No. 2/2005. - March, 12005 (In Russian)

9. Siaw, M.O., Ofosu, I.W., Lutterodt, H.E., Ankar- Brewoo, G.M. (2018) Acrylamide exposure and risks in most frequently consumed foods in a total diet study. American Journal of Food Science and Technology, 6(4), 123-137.

10. Bessonov, V.V., Malinkin, A.D., Perederyaev, O.I., Bogachuk, M.N. Volovich, S.V., Medvedev, Yu.V. (2011). Development of methods for determining acrylamide in food products by gas- liquid chromatography. Voprosy Pitaniia, 80(4), 79-83. (In Russian)

11. Tareke, E., Rydberg, P., Karlsson, P., Eriksson, S., Tornqvist, M. (2002). Analysis of acrylamide, a carcinogen formed in heated foodstuffs. Journal of Agricultural and Food Chemistry, 50(17), 4998-5006.

12. Acrylamide in food: Request for comments and for Scientific Data and information. Food and drug Administration, HHS Federal Register: August 26, 2009. 74(164), 43134-43138.

13. Neklyudov, A.D., Ivankin, A.N., Berdutina, A.V. (2003). Principles of Biochemical Processing of Animal and Combined Feedstock. M: VNIIMP. - 115 p. ISBN: 5- 901768-12- 4. (In Russian)

14. Neklyudov, A.D., Ivankin, A.N., Berdutina, A.V. (2000). Properties and uses of protein hydrolysates. Applied Biochemistry and Microbiology, 36(5), 452-459.

15. Bagryantseva, O.V., Shatrov G.N., Khotimchenko S.A. (2010). Acrylamide. Its synthesis in processed food and ways of problem solution. Voprosy Pitaniia, 79(1), 4-12. (In Russian)

16. Mazur, A.M., Ban', M.F. (2006). The possible ways of reduction of acrylamide content in food products. Storage and processing of farm products, 5, 22-24. (In Russian)

17. Nilova, L.P., Malyutenkova, S.M., Vytovtov, A.A. (2017). The safety of bakery products: acrylamide. Bulletin of South Ural State University, Series "Food and Biotechnology", 5(1), 74-81. (In Russian)

\section{AUTHOR INFORMATION}

Andrei S. Dydykin - candidate of technical sciences, docent, Head of the Department of functional and specialized nutrition, V.M. Gorbatov Federal Research Center for Food Systems of Russian Academy of Sciences, 109316, Moscow, Talalikhina str., 26, Tel.: +7-495-676-75-41, E-mail: a.didikin@fncps.ru *corresponding author

Olga K. Derevitskaya - candidate of technical sciences, leading research scientist, Department of functional and specialized nutrition), V.M. Gorbatov Federal Research Center for Food Systems of Russian Academy of Science, 109316, Moscow, Talalikhina str., 26, Tel.: +7 -495- 676-96-18, E-mail: o.derevickaya@fncps.ru

Andrew N. Ivankin - doctor of chemical sciences, professor, academician of the International Higher Education Academy of Sciences, Head of the Department of Chemistry, Bauman Moscow State Technical University, 141005, Mitishi, 1-st Institutskaya str., 1, Tel.: +7-498-687-36-00, e-mail: aivankin@inbox.ru

Andrey V. Kulikovskii - candidate of technical sciences, a head chromatography laboratory, leading scientific worker of the Laboratory «Scientific and methodical work, biological and analytical research», V.M. Gorbatov Federal Research Center for Food Systems of Russian Academy of Sciences, 109316, Moscow, Talalikhina str., 26, Tel.: +7-495-676-79-61, E-mail: a.kulikovskii@fncps.ru

Ekaterina I. Dragunskaya - research engineer, Department of functional and specialized nutrition, V.M. Gorbatov Federal Research Center for Food Systems of Russian Academy of Sciences, 109316, Moscow, Talalikhina str., 26, Tel.: +7 -495- 676-62-01, E-mail: e.dragunskaya@fncps.ru Authors are equally relevant to the writing of the manuscript, and equally responsible for plagiarism The authors declare no conflict of interest

Received 30.11.2018 Accepted in revised 21.01.2018 Accepted for publication 12.02.2019 